\title{
Thermal structure and basal sliding parametrisation at Pine Island Glacier - a 3-D full-Stokes model study
}

\author{
N. Wilkens ${ }^{1,2}$, J. Behrens ${ }^{3}$, T. Kleiner ${ }^{2}$, D. Rippin ${ }^{4}$, M. Rückamp ${ }^{2}$, and A. Humbert ${ }^{2,5}$ \\ ${ }^{1}$ Institute for Geophysics, University of Hamburg, Germany \\ ${ }^{2}$ Alfred Wegener Institute, Helmholtz Centre for Polar and Marine Research, Bremerhaven, Germany \\ ${ }^{3}$ Numerical Methods in Geosciences, University of Hamburg, Germany \\ ${ }^{4}$ Environment Department, University of York, Heslington, UK \\ ${ }^{5}$ Department of Geosciences, University of Bremen, Germany \\ Correspondence to: N. Wilkens (nina.wilkens@zmaw.de)
}

Received: 21 August 2014 - Published in The Cryosphere Discuss.: 16 September 2014

Revised: 16 March 2015 - Accepted: 17 March 2015 - Published: 13 April 2015

\begin{abstract}
Pine Island Glacier is one of the fastest changing glaciers of the Antarctic Ice Sheet and therefore of scientific interest. The glacier holds enough ice to raise the global sea level significantly $(\sim 0.5 \mathrm{~m})$ when fully melted. The question addressed by numerous modelling studies of the glacier focuses on whether the observed changes are a start of an uncontrolled and accelerating retreat. The movement of the glacier is, in the fast-flowing areas, dominated by basal motion. In modelling studies the parametrisation of the basal motion is therefore crucial. Inversion methods are commonly applied to reproduce the complex surface flow structure of Pine Island Glacier by using information of the observed surface velocity field to constrain, among other things, basal sliding. We introduce two different approaches of combining a physical parameter, the basal roughness, with basal sliding parametrisations. This way basal sliding is again connected closer to its original formulation. We show that the basal roughness is an important and helpful parameter to consider and that many features of the flow structure can be reproduced with these approaches.
\end{abstract}

\section{Introduction}

In the past decades the fastest changes in ice flow velocity, ice thickness and grounding line retreat in the Antarctic Ice Sheet have been observed in the region of Pine Island Glacier (PIG), Amundsen Sea Embayment, West Antarctica (Rignot, 2008, 1998; Wingham et al., 2009; Joughin et al., 2010;
Park et al., 2013; Helm et al., 2014). Additionally, the currently observed mass loss from the Antarctic Ice Sheet is also concentrated in the area around PIG (Horwath and Dietrich, 2009; Shepherd et al., 2012). Thus PIG shows an increased contribution to global sea level rise (Mouginot et al., 2014).

The bed lies below sea level in large areas, making it part of a so-called marine ice sheet. In combination with a retrograde bed, which slopes down from the ocean towards the centre of the glacier, this setting was postulated to be intrinsically unstable by the so-called "Marine Ice Sheet Instability" hypothesis (Hughes, 1973). This hypothesis is still up for debate (Vaughan, 2008; Gudmundsson et al., 2012), while the trigger for the changes is thought to be enhanced ocean melting of the ice shelf (Dutrieux et al., 2014).

The dynamics of PIG are crucial to its future behaviour and therefore to its contribution to sea level rise. Due to the fast changes observed at PIG, a variety of modelling studies have been conducted. These studies address questions focusing on the sensitivity to changes in external conditions (ice shelf buttressing, basal conditions) (e.g. Schmeltz et al., 2002) and on the contribution to future sea level rise (e.g. Joughin et al., 2010). The overarching question is whether the system will stabilise again in the near future or whether retreat may even accelerate (e.g. Katz and Worster, 2010; Gladstone et al., 2012; Favier et al., 2014; Seroussi et al., 2014).

Ice flow models simulate glacier ice flow which is due to a combination of internal deformation and basal motion. Depending on the subglacial setting, basal motion can dominate 
the overall motion of a glacier, which is also the case for large areas of PIG. Therefore, the basal sliding behaviour might be the crucial process to cause a further retreat or halt of the system. Gudmundsson et al. (2012) show that stable grounding line positions can be found on a retrograde bed using models with two horizontal dimensions. The basal sliding behaviour could be a similarly important process as the lateral buttressing.

On the one hand, the parametrisation of basal motion in ice flow models is important for the overall dynamics of a glacier. On the other hand, the difficulty of observing basal properties renders the parametrisation one of the most challenging parts of ice flow modelling. In the absence of information on basal properties like bed type, structure and availability of liquid water, control methods are applied to simulate a complex glacier flow pattern, such as that present at PIG (e.g. MacAyeal, 1992; Joughin et al., 2009, 2010; Morlighem et al., 2010; Seroussi et al., 2014; Favier et al., 2014). These methods use the measured surface velocity field to invert for basal properties or effective viscosity and to adjust basal sliding parameters. Depending on the focus of the study, these approaches can provide important insights into glacier dynamics.

The prognostic studies on PIG all use control methods to constrain basal sliding. Thus they define a spatially varying basal sliding parameter for the present flow state and keep it constant during the prognostic simulations. This way the basal sliding is somehow decoupled from the rest of the system. As the observable surface velocity field is a superposition of basal motion (sliding and bed deformation) and ice deformation, an inversion for basal sliding may introduce errors in the basal sliding that compensate for errors in the deformational part of the ice velocity. This is especially important for the strong temperature dependence of the flow rate factor used for the ice viscosity. In addition, the spatial distribution of a basal sliding parameter represents not only the flow state at a specific time of observation, but also the assumed thermal state in the model at the same time. One could imagine that an area with significant sliding at the time of the inversion could freeze at later time steps but is allowed to slide at all times.

As the inversion for basal sliding parameters is not sufficient for the physical understanding of basal motion, we focus on basal sliding parametrisations that consider measured basal roughness distributions. This accessible bed information could in further steps be combined with, for example, a sufficient realistic and time-dependent hydrological model to consider changing basal conditions for the sliding behaviour of the glacier.

Here we present results of the thermomechanical 3-D fullStokes model COMice (implemented in the COMmercial finite element SOLver COMSOL Multiphysics ${ }^{\odot}$, cf. Wilkens, 2014) applied diagnostically to PIG. Initially we conduct a diagnostic inversion for a basal sliding parameter, as done in previous studies, to generate a reference simulation and analyse the thermal structure of the glacier. In subsequent experiments we introduce two methods of connecting basal roughness measures to the parametrisation of basal sliding and therefore constrain basal sliding with more physically justified assumptions. Additionally, we couple the sliding behaviour to the basal temperature, adding another physically based constraint. The first method matches a singleparameter basal roughness measure for PIG, as presented in Rippin et al. (2011), onto a basal sliding parameter. The second method is based on ideas from $\mathrm{Li}$ et al. (2010), with a two-parameter basal roughness measure which we apply to connect basal roughness to basal sliding.

\section{The numerical flow model}

\subsection{Governing equations}

The governing equations for the thermomechanical ice flow model COMice are the fluid dynamical balance equations together with a formulation for the non-Newtonian rheology of ice. The balance equations are set up for mass, momentum and energy and solved for the velocity vector $\boldsymbol{u}$, pressure $p$ and temperature $T$.

The mass balance equation is given in case of incompressibility as

$\operatorname{div} \boldsymbol{u}=0$.

The momentum balance equation is the Stokes equation, given by

$\operatorname{div} \sigma=-\rho_{\mathrm{i}} \boldsymbol{g}$,

with the Cauchy stress tensor $\sigma$, the density of ice $\rho_{\mathrm{i}}$ and the acceleration of gravity $\boldsymbol{g}=(0,0,-g)^{T}$. The stress tensor $\sigma$ is split into a velocity dependent part $\tau$, the deviatoric stress, and a pressure dependent part $p \mathbf{I}$ with the identity matrix $\mathbf{I}$, such that $\sigma=\boldsymbol{\tau}-p \mathbf{I}$. For incompressible materials only the deviatoric stress $\boldsymbol{\tau}$ can result in strains and is thus related to the velocity field $\boldsymbol{u}$ via the strain-rate tensor $\dot{\boldsymbol{\varepsilon}}$ and the effective viscosity $\mu$, such that $\boldsymbol{\tau}=2 \mu \dot{\boldsymbol{\varepsilon}}$. The strain-rate tensor $\dot{\boldsymbol{\varepsilon}}$ is given in components as

$\dot{\varepsilon}_{i j}=\frac{1}{2}\left(\frac{\partial u_{i}}{\partial x_{j}}+\frac{\partial u_{j}}{\partial x_{i}}\right)$,

in relation to Cartesian basis vectors. The effective viscosity $\mu$ is described with use of Glen's flow law (Glen, 1955; Nye, 1957), such that

$\mu\left(T^{\prime}, \dot{\varepsilon}_{\mathrm{e}}\right)=\frac{1}{2}\left(A\left(T^{\prime}\right)\right)^{-1 / n} \dot{\varepsilon}_{\mathrm{e}}^{(1-n) / n}$,

with the rate factor $A\left(T^{\prime}\right)$, the stress exponent $n$ and the effective strain rate

$\dot{\varepsilon}_{\mathrm{e}}=\sqrt{\frac{1}{2} \operatorname{tr}\left(\dot{\varepsilon}^{2}\right)}$ 
which is the second invariant of the strain-rate tensor $\dot{\varepsilon}$. The homologous temperature $T^{\prime}$ is the temperature relative to the pressure melting point $T_{\mathrm{pmp}}$, defined as

$T^{\prime}=T+\beta_{\mathrm{c}} p$,

with the Clausius-Clapeyron constant $\beta_{\mathrm{c}}$. The pressure melting point $T_{\mathrm{pmp}}$ is described for typical pressures in ice sheets $(p \lesssim 50 \mathrm{MPa})$ by a linear relation, such that

$T_{\mathrm{pmp}}=T_{0}-\beta_{\mathrm{c}} p$,

with the melting point at low pressures $T_{0}$. The rate factor $A\left(T^{\prime}\right)$ parametrises the influence of the temperature and the pressure onto the viscosity $\mu$ and is described by $A\left(T^{\prime}\right)=$ $A_{0} e^{-Q / R T^{\prime}}$ (Greve and Blatter, 2009), with a pre-exponential constant $A_{0}$, the activation energy for creep $Q$ and the gas constant $R$.

The energy balance equation is given as

$$
\rho c_{\mathrm{p}}(T)\left(\frac{\partial T}{\partial t}+\boldsymbol{u} \operatorname{grad} T\right)=\operatorname{div}(\kappa(T) \operatorname{grad} T)+\psi,
$$

with thermal conductivity $\kappa(T)$, specific heat capacity $c_{\mathrm{p}}(T)$ and an internal heat source term $\psi=4 \mu \dot{\varepsilon}_{e}^{2}$ which connects mechanical and thermal energy.

\subsection{Boundary conditions}

The balance equations are defined under the assumption that the thermodynamic fields are sufficiently smooth and thus continuously differentiable, which is only the case for the inner parts of the glacier. The outer boundaries need specifically formulated boundary conditions. The vertical boundaries are the upper surface $z_{\mathrm{s}}$ and the base $z_{\mathrm{b}}$ of the glacier. The lateral boundaries are given by the ice divide, an inflow area and the calving front. The grounding line indicates the change of the basal boundary conditions from grounded to floating ice.

\subsubsection{Stokes flow}

The upper surface can be seen to be traction free by assuming that wind stress and atmospheric pressure are negligible compared to the typical stresses in the ice sheet, such that $\boldsymbol{\sigma} \cdot \boldsymbol{n}=0$.

Since the model is applied in a diagnostic manner and therefore the geometry is fixed, only the ice base needs a kinematic boundary condition to prevent the flow to point into the ground and is given as $\boldsymbol{u} \cdot \boldsymbol{n}=0$, with the unit normal vector $\boldsymbol{n}$ pointing outwards from the surface. This Dirichlet condition is applied to the entire ice base, including grounded and floating parts, and also implies that no basal melting is considered.

At the base of the floating ice shelf shear stress induced by circulating sea water can be neglected (Weis et al., 1999) and the only stress onto the ice is exerted by hydrostatic water pressure. As the ice shelf floats it is assumed to fulfil the floating condition and the stress applied equals the stress of the displaced water column (Greve and Blatter, 2009), such that

$\boldsymbol{\sigma} \cdot \boldsymbol{n}=-p_{\mathrm{sw}} \boldsymbol{n}$,

with the water pressure $p_{\text {sw }}$ defined as

$p_{\mathrm{sw}}= \begin{cases}0 & \text { for } \quad z \geq z_{\mathrm{sl}} \\ \rho_{\mathrm{sw}} g\left(z_{\mathrm{sl}}-z\right) & \text { for } \quad z<z_{\mathrm{sl}},\end{cases}$

with the density of sea water $\rho_{\mathrm{sw}}$ and the mean sea level $z_{\mathrm{sl}}$. Thus, the boundary conditions at the ice shelf base read

$$
\begin{aligned}
& \boldsymbol{u} \cdot \boldsymbol{n}=0, \quad(\boldsymbol{\sigma} \cdot \boldsymbol{n}) \cdot \boldsymbol{t}_{x}=0 \quad \text { and } \\
& (\boldsymbol{\sigma} \cdot \boldsymbol{n}) \cdot \boldsymbol{t}_{y}=0 .
\end{aligned}
$$

with the unit tangential vectors $\boldsymbol{t}_{x}$ in the $x z$ plane and $\boldsymbol{t}_{y}$ in the $y z$ plane.

For the boundary condition of the grounded ice, it is assumed that the stress vector $\boldsymbol{\sigma} \cdot \boldsymbol{n}$ is continuous across the interface such that $\boldsymbol{\sigma} \cdot \boldsymbol{n}=\boldsymbol{\sigma}_{\text {lith }} \cdot \boldsymbol{n}$, with the Cauchy stress ten-

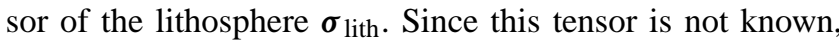
the condition has to be approximated. This is done with a sliding law that connects the basal sliding velocity $\boldsymbol{u}_{\mathrm{b}}=$ $\left(\boldsymbol{u} \cdot \boldsymbol{t}_{x}, \boldsymbol{u} \cdot \boldsymbol{t}_{y}\right)^{T}$ to the basal drag $\boldsymbol{\tau}_{\mathrm{b}}=\left((\boldsymbol{\sigma} \cdot \boldsymbol{n}) \cdot \boldsymbol{t}_{x},(\boldsymbol{\sigma} \cdot \boldsymbol{n}) \cdot \boldsymbol{t}_{y}\right)^{T}$.

So-called "Weertman-type sliding laws" are commonly applied in ice flow modelling studies, of which the basis was established by Weertman (1957). He developed a mathematical description for the mechanisms that influence basal sliding. One focus lay hereby on connecting small-scale processes with larger-scale sliding effects. Nye (1969) and Kamb (1970) worked on related problems and they all found that the basal sliding velocity $\boldsymbol{u}_{\mathrm{b}}$ varies with some power of the basal shear stress $\boldsymbol{\tau}_{\mathrm{b}}$, depending on the dominant mechanism. Additionally they find that the sensitively of basal sliding velocity $\boldsymbol{u}_{\mathrm{b}}$ depends on the roughness of the bed.

The processes considered by Weertman (1957), Nye (1969) and Kamb (1970) are only relevant for sliding over hard bedrock, where an upper limit for sliding velocities is found $\left(\boldsymbol{u}_{\mathrm{b}}<20 \mathrm{~m} \mathrm{a}^{-1}\right.$; Cuffey and Paterson, 2010). For faster sliding velocities, weak deformable substrate or water-filled cavities have to be present. Water-filled cavities reduce the contact between the ice and the bedrock, therefore effectively reducing the roughness of the bed; their effect can be considered via the effective pressure $N_{\mathrm{b}}=-N_{\mathrm{b}} \cdot \boldsymbol{n}$ (Bindschadler, 1983). Fast sliding velocities can only occur when the glacier base is at pressure melting point, but some sliding can also be present below these temperatures (Fowler, 1986). This mechanism can be reflected by a temperature function $f(T)$, which regulates sub-melt sliding. Considering the above-stated thoughts leads to a sliding law of the form

$\boldsymbol{u}_{\mathrm{b}}=C_{\mathrm{b}}\left|\boldsymbol{\tau}_{\mathrm{b}}\right|^{p-1} N_{\mathrm{b}}^{-q} f(T) \boldsymbol{\tau}_{\mathrm{b}}=\frac{1}{\beta^{2}} \boldsymbol{\tau}_{\mathrm{b}}$, 
whereby $C_{\mathrm{b}}$ is originally seen as a roughness parameter and $p$ and $q$ are basal sliding exponents. When written in a linearised form, all effects influencing the basal sliding velocity $\boldsymbol{u}_{\mathrm{b}}$, other than the linear relation to the basal shear stress $\boldsymbol{\tau}_{\mathrm{b}}$, are summarised in a basal sliding parameter $\beta^{2}$.

The overburden pressure of the ice is reduced in marine parts by the uplifting water pressure (Huybrechts, 1992), such that

$N_{\mathrm{b}}= \begin{cases}\rho_{\mathrm{i}} g H & \text { for } \quad z_{\mathrm{b}} \geq z_{\mathrm{sl}} \\ \rho_{\mathrm{i}} g H+\rho_{\mathrm{sw}} g\left(z_{\mathrm{b}}-z_{\mathrm{sl}}\right) & \text { for } \quad z_{\mathrm{b}}<z_{\mathrm{sl}},\end{cases}$

where $H$ is the ice thickness. The assumptions made above imply that the base is perfectly connected to the ocean at any location in the domain that is below sea level. This assumption is plausible near the grounding line but becomes highly speculative towards the marine regions further inland. An additional hydrological model would be needed to realistically simulate the effective basal pressure but is beyond the scope of this study. Even though more sophisticated parametrisations for the effective pressure exist (e.g. Leguy et al., 2014), we stick with the strong assumption stated above, as water is likely present below all fast-flowing parts of PIG (Smith et al., 2013) which coincide with the marine regions. Equation (13) further implies that the overburden pressure is cryostatic and neglects the dynamic contribution from the Stokes solution to the pressure. In general, the dynamic part is small compared to the cryostatic part, even if the bed is rough or sliding changes over short distances (Pattyn et al., 2008, in the Supplement).

The temperature function $f(T)$ is taken, as suggested by Budd and Jenssen (1987), as an exponential function such that

$f(T)=e^{v\left(T-T_{\mathrm{pmp}}\right)}$,

with a sub-melt sliding parameter $v$.

The dynamic boundary condition at the base is implemented with a tangential part (Eq. 12) and a normal part (Eq. 13) such that

$$
\begin{array}{ll}
\boldsymbol{u} \cdot \boldsymbol{n}=0, & (\boldsymbol{\sigma} \cdot \boldsymbol{n}) \cdot \boldsymbol{t}_{x}=\beta^{2} \boldsymbol{u} \cdot \boldsymbol{t}_{x} \quad \text { and } \\
& (\boldsymbol{\sigma} \cdot \boldsymbol{n}) \cdot \boldsymbol{t}_{y}=\beta^{2} \boldsymbol{u} \cdot \boldsymbol{t}_{y} .
\end{array}
$$

The stress boundary condition is a Robin boundary condition as it depends on the velocity and the velocity gradients. With $\beta^{2}=0$ for the floating part, this boundary condition equals Eq. 11.

Ice divides can be seen as mirror points where the direction of the driving stress and flow on one side of the divide opposes that of the other side. No flow across the ice divide is allowed, the tangential stresses vanish and therefore the boundary condition for ice divides is given by

$$
\boldsymbol{u} \cdot \boldsymbol{n}=0, \quad \begin{array}{ll}
(\boldsymbol{\sigma} \cdot \boldsymbol{n}) \cdot \boldsymbol{t}_{x}=0 \quad \text { and } \\
(\boldsymbol{\sigma} \cdot \boldsymbol{n}) \cdot \boldsymbol{t}_{y}=0,
\end{array}
$$

with the unit normal vector $\boldsymbol{n}$ pointing outwards from the surface and lying in the $x y$ plane.

The boundary condition at the vertical calving front is given by Eq. (9) and Eq. (10), where the normal vector is pointing towards the ocean and lies in the $x y$ plane. For the inflow region a Dirichlet condition prescribes an inflow velocity field calculated analytically with the shallow ice approximation (Hutter, 1983; Morland, 1984). A no-slip condition is assigned to the outer wall of the ice rises, as they are implemented as holes in the geometry.

\subsubsection{Temperature}

The boundary conditions for the upper surface is given by Dirichlet conditions in prescribing the average annual surface temperature $T_{\mathrm{S}}(x, y, t)$. At the base of the grounded ice two cases are to be distinguished. For a cold base, that is a basal temperature below the pressure melting point, the boundary condition has to be formulated as a Neumann condition and the temperature gradient is prescribed as

$\operatorname{grad} T \cdot \boldsymbol{n}=\frac{q_{\mathrm{geo}}+q_{\mathrm{fric}}}{\kappa(T)}$,

with the geothermal flux $q_{\text {geo }}$ and the friction heating due to basal sliding $q_{\text {fric }}=\boldsymbol{u}_{\mathrm{b}} \cdot \boldsymbol{\tau}_{\mathrm{b}}$ (Pattyn, 2003). If the basal temperature reaches the pressure melting point in the grounded part or the freezing temperature of seawater $T_{\mathrm{sw}}$ in the floating part, it has to be switched to a Dirichlet condition:

$T= \begin{cases}T_{\mathrm{pmp}} & \text { if grounded, } \\ T_{\mathrm{sw}} & \text { if floating. }\end{cases}$

The boundary condition for the ice divide and the calving front are based on the assumption that there is no temperature gradient across the surface. It can thus be written in the form of a thermal insulation $(\kappa(T) \operatorname{grad} T) \cdot \boldsymbol{n}=0$. Lastly, temperatures at the inflow boundary are prescribed by a linear profile $T_{\text {lin }}=\frac{T_{\mathrm{pmp}}-T_{\mathrm{s}}}{z_{\mathrm{s}}-z_{\mathrm{b}}}\left(z_{\mathrm{s}}-z\right)+T_{\mathrm{s}}$.

\subsection{Implementation}

The thermomechanically coupled 3-D full-Stokes model COMice is implemented in the COMmercial finite element SOLver COMSOL Multiphysics ${ }^{\circledR}$ (cf. Wilkens (2014) for implementation details). The model has been successfully applied in the diagnostic tests in the MISMIP 3-D model intercomparison project (Pattyn et al., 2013) and the ISMIPHOM experiments (Pattyn et al., 2008). The ice flow model solves for the velocity vector $\boldsymbol{u}$, the pressure $p$ and the temperature $T$. The unstabilised Stokes equation (Eq. 2) is subject to the Babuska-Brezzi condition, which states that the basis functions for $p$ have to be of lower order than for $\boldsymbol{u}$. Therefore, we use linear elements for $p$ and quadratic elements for $\boldsymbol{u}(\mathrm{P} 1+\mathrm{P} 2)$. The energy balance equation Eq. (8) is discretized with linear elements. To avoid numerical instabilities due to strong temperature advection, and thus to 
ensure that the element Péclet number is always $<1$, we use consistent stabilisation methods provided by COMSOL. Eq. (8) is solved using a Galerkin least-square formulation (Codina, 1998) in streamline direction and crosswind diffusion (Hauke and Hughes, 1998) orthogonal to the streamline direction. The chosen stabilisation methods add less numerical diffusion the closer the numerical solution comes to the exact solution.

To the effective strain rate $\dot{\varepsilon_{\mathrm{e}}}$ (Eq. 5) a small value of $10^{-30} \mathrm{~s}^{-1}$ is added to keep the term non-zero. Model experiments have shown that this does not affect the overall results (Pattyn, 2003; Cornford et al., 2012). The scalar values for all parameters used throughout this study are listed in Table 1.

All Dirichlet boundary conditions are implemented as a weak constraint, which means that constraints are enforced in a local average sense. This gives a smoother result than the standard method in COMSOL where constraints are enforced pointwise at node points in the mesh. The Neumann condition (Eq. 17), together with the Dirichlet condition for the basal temperature at the base (Eq. 18), is implemented in a way that a switch between these two types is avoided. This is done because a jump from $T_{\mathrm{pmp}}$ to $T_{\mathrm{sw}}$ in the area of the grounding line leads to non-convergence of the flow model. Therefore, a heat flux is prescribed as long as $T<$ $\left(T_{\mathrm{b}, \max }-0.01\right)$. The expression $T_{\mathrm{b}, \max }$ prescribes a spatially variable field that defines the maximal basal temperature allowed for a region ( $T_{\mathrm{pmp}}$ for grounded areas, $T_{\mathrm{sw}}$ for floating areas). If $T \geq\left(T_{\mathrm{b}, \max }-0.01\right)$, the heat flux is gradually reduced and becomes zero when $T=\left(T_{\mathrm{b}, \max }+0.01\right)$. This procedure ensures that the basal heat flux can not increase $T_{\mathrm{b}}$ above $T_{\mathrm{b}, \max }+0.01$. The smoothing of the step function ensures numerical stability, which was not found with a sharp step. The implementation is similar as in Aschwanden and Blatter (2009).

\subsubsection{Mesh}

To maximise the resolution while minimising the amount of elements, we use an unstructured finite element mesh. The upper surface is meshed first with triangles. The horizontal edge lengths are $5-500 \mathrm{~m}$ at the grounding line and the calving front, $50-1000 \mathrm{~m}$ at the inflow area and $100-2000 \mathrm{~m}$ at the rest of the outer boundary. The resulting 2-D surface mesh is extruded through the glacier geometry with a total of 12 vertical layers everywhere. The thickness of the vertical layers varies only with ice thickness. The spacing between the layers is refined towards the base. The ratio of the lowest to the upper most layer thickness is 0.01 , leading to a thickness of the lowest layer of about $5 \mathrm{~m}$ for a total ice thickness of $3000 \mathrm{~m}$. The final mesh consists of $\sim 3.5 \times 10^{5}$ prism elements, which results in $\sim 5 \times 10^{6}$ degrees of freedom (DOF) when solved for all variables.

\subsubsection{Solver}

For solving the nonlinear system, a direct segregated solver is used which conducts a quasi-Newton iteration. It solves consecutively: first for the velocity $\boldsymbol{u}$ and the pressure $p$ and thereafter for the temperature $T$ (COMSOL, 2012). This allows for reduced working memory usage. For the remaining linear systems of equations, the direct solver Pardiso (COMSOL (2012) and http://www.pardiso-project.org/, last access: 9 December 2014) is applied. While uncommon for such large numbers of DOF, it proved to be computationally viable and robust.

\section{Data}

\subsection{Geometry}

The geometry of the model was built with a consistent set of surface elevation, ice thickness and bed topography on a $1 \mathrm{~km}$ grid, created by A. Le Brocq and kindly provided by her for this work. The data set represents the thickness distribution of PIG for the year 2005 and earlier. The Le Brocq data are based on the surface elevation data of Bamber et al. (2009) and the ice thickness data of Vaughan et al. (2006). The grounding line position used is given by a combination of the positions in the MODIS Mosaic Of Antarctica (Bohlander and Scambos, 2007) corresponding to the years 2003/2004, the position in Rignot (1998), corresponding to 1996 and the positions that give the smoothest ice thickness joined between grounded and floating ice, assuming the floatation condition. The model domain and grounding line are indicated in Fig. 1. The location of the ice rises pinning the ice shelf at present are detected on TerraSAR-X images from 2011, with assistance of interferograms from Rignot (2002). Please note that ice rises are not indicated in Fig. 1.

\subsection{Ice flow velocity}

The observed surface velocity is taken from Rignot et al. (2011), shown in Fig. 1, and used to validate the reference simulation. The numbering of the 1-10 tributaries feeding the central stream is based on Stenoien and Bentley (2000). The numbering used in Vaughan et al. (2006), Karlsson et al. (2009) and Rippin et al. (2011) is the same for the even numbers but shifted by 1 for the odd numbers, as they missed tributary 1 from the numbering by Stenoien and Bentley (2000). We extended the numbering from Stenoien and Bentley (2000) to the tributaries 11-14, which are entering the ice shelf. Finally, Fig. 1 indicates the locations of the different types of lateral boundaries (ice divide, inflow and calving front). 


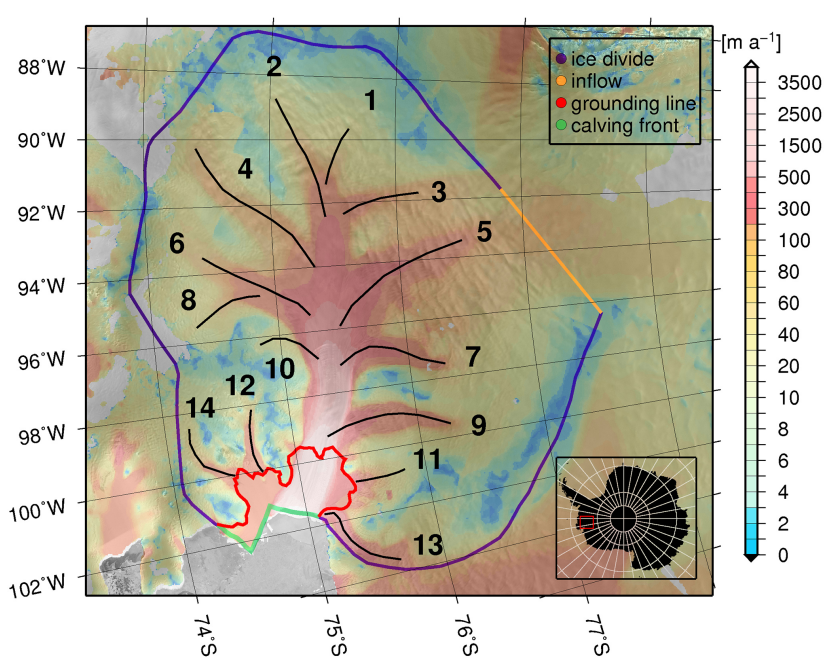

Figure 1. RADARSAT Antarctic Mapping Project (RAMP) mosaic with the observed surface velocities from Rignot et al. (2011) and the model domain of Pine Island Glacier, with the different lateral boundaries, the grounding line and the numbered tributaries indicated.

\subsection{Temperature}

The surface temperature used here is on a $5 \mathrm{~km}$ grid compiled by Le Brocq et al. (2010) (ALBMAP v1), based on the temperature data described in Comiso (2000). We use the geothermal flux $q_{\text {geo }}$ from Purucker (2012, updated version of Fox Maule et al., 2005), because a variety of sensitivity tests showed that other data sets lead to too-high velocities in regions with no or little basal sliding.

\subsection{Roughness}

In this study we use two different measurements of basal roughness beneath the PIG. The first one is the singleparameter roughness measure as presented in Rippin et al. (2011) (cf. Fig. 4b therein) and represents the methodology often employed to define subglacial roughness (Hubbard et al., 2000; Taylor et al., 2004; Siegert et al., 2004, 2005; Bingham and Siegert, 2007; Bingham et al., 2007; Rippin et al., 2011). This usual approach effectively provides a measure of bed obstacle amplitude or vertical roughness. The second measure, which we calculate for this study, follows the work of Li et al. (2010), Wright et al. (2012) and more recently Rippin et al. (2014). They introduce a second parameter which effectively provides a further measure of the frequency or wavelength of roughness obstacles (Rippin et al., 2014). Both roughness measures are based on fast Fourier transforms (FFTs). FFT can be used to transform any surface into a sum of several periodically undulated surfaces. In a number of recent glaciological studies, basal topography data are transformed into a single-parameter roughness measure $(\xi)$ which is defined as the integral of the spectrum within a specified wavelength interval. This method represents the amplitude of the undulations, but information about the frequency is lost. For PIG the single-parameter roughness measure $\xi$ was calculated by Rippin et al. (2011) from a RES data set generated in austral summer 2004/05 (Vaughan et al., 2006). It is the same data set the model geometry is based on (Sect. 3), although the roughness measure includes higher-resolution information as the derivation is based on along-track sample spacing of the order of $30 \mathrm{~m}$ (cf. Rippin et al., 2011). Both data sets are then gridded with $1 \mathrm{~km} \mathrm{spac}-$ ing.

By applying the work of $\mathrm{Li}$ et al. (2010), we introduce a second parameter so that as well as being able to represent the amplitude $(\xi)$, we are also able to explore the frequency $(\eta)$ of the undulations. This measure is calculated as the total roughness divided by the bed slope roughness (Rippin et al., 2014). Li et al. (2010) provide guidance on how to interpret these two parameters in terms of their different basal topographies, along with their geomorphic implications. The interpretation from Li et al. (2010) is based on ideas by Bingham and Siegert (2009) which give an interpretation for the single-parameter roughness. Rippin et al. (2014) extended the interpretation for the two-parameter roughness measure. The implications for PIG will be discussed below.

Because of the statistical meanings of $\xi$ and $\eta$, they can be used as representatives for the vertical and horizontal length scales present at the base. To do so the integration interval for $\{\xi, \eta\}$ should be in the metre-scale waveband (Li et al., 2010). The two-parameter roughness measure for PIG was calculated for this study. The spatial resolution of the underlain data for PIG is $34 \mathrm{~m}$. A moving window is calculated with $N=5\left(2^{N}=32\right)$, which is the minimum for $N$ that should be used (e.g. Taylor et al., 2004). With a spatial resolution of $34 \mathrm{~m}$ this leads to a moving window length of $1088 \mathrm{~m}$, which is in the metre-scale waveband required by Li et al. (2010), to be able to apply the data in a sliding relation.

The received fields of $\xi$ and $\eta$ for PIG are shown in Fig. 2. According to Li et al. (2010), different basal properties and related geomorphic implications can be distinguished from patterns of $\xi$ and $\eta$. A marine setting with intensive deposition and fast and warm ice flow, as proposed for the central part of PIG, is characterised by low values of $\xi$ and high values of $\eta$, thus low-amplitude, low-frequency roughness. Here it has to be noted that the second parameter $\eta$ should be more accurately seen as representing the wavelength of roughness, rather than the frequency, as high values correspond to low frequencies (Rippin et al., 2014). Nonetheless we continue here referring to $\eta$ as the roughness frequency for consistency with $\mathrm{Li}$ et al. (2010). The suspected low-amplitude, low-frequency roughness is not necessarily found in the central trunk area, as can be seen in Fig. 2. Instead it seems to be more dominated by low-amplitude, high-frequency roughness which can, following Li et al. (2010), be interpreted as a continental setting after intensive erosion, also with fast and warm ice flow. Still, this interpretation can not be seen as a 
Table 1. Parameter values.

\begin{tabular}{|c|c|c|c|}
\hline Parameter & Value & Unit & Description \\
\hline$\rho_{\mathrm{i}}$ & 918 & $\mathrm{~kg} \mathrm{~m}^{-3}$ & Ice density \\
\hline$\rho_{\mathrm{sW}}$ & 1028 & $\mathrm{~kg} \mathrm{~m}^{-3}$ & Seawater density \\
\hline$g$ & 9.81 & $\mathrm{~ms}^{-2}$ & Acceleration of gravity \\
\hline$n$ & 3 & & Stress exponent \\
\hline$R$ & 8.314 & $\mathrm{~J} \mathrm{~mol}^{-1} \mathrm{~K}^{-1}$ & Gas constant \\
\hline$Q$ & $\begin{array}{l}60 \text { for } T^{\prime} \leq 263.15 \mathrm{~K} \\
139 \text { for } T^{\prime}>263.15 \mathrm{~K}\end{array}$ & $\mathrm{~kJ} \mathrm{~mol}^{-1}$ & $\begin{array}{l}\text { Activation energy for creep } \\
\text { (Paterson, 1994) }\end{array}$ \\
\hline$A_{0}$ & $\begin{array}{l}3.985 \times 10^{-13} \text { for } T^{\prime} \leq 263.15 \mathrm{~K} \\
1.916 \times 10^{3} \text { for } T^{\prime}>263.15 \mathrm{~K}\end{array}$ & $\mathrm{~s}^{-1} \mathrm{~Pa}^{-3}$ & $\begin{array}{l}\text { Pre-exponential constant } \\
\text { (Paterson, 1994) }\end{array}$ \\
\hline$T_{0}$ & 273.15 & $\mathrm{~K}$ & Melting point for low pressures \\
\hline$\beta_{\mathrm{c}}$ & $9.8 \times 10^{-8}$ & $\mathrm{KPa}^{-1}$ & $\begin{array}{l}\text { Clausius-Clapeyron constant } \\
\text { (Hooke, 2005) }\end{array}$ \\
\hline$T_{\mathrm{sw}}$ & 271.15 & $\mathrm{~K}$ & Freezing temperature of seawater \\
\hline$v$ & 0.1 & & $\begin{array}{l}\text { Sub-melt sliding parameter } \\
\text { (Budd and Jenssen, 1987) }\end{array}$ \\
\hline$\kappa(T)$ & $9.828 e^{\left(-5.7 \times 10^{-3} T\left[\mathrm{~K}^{-1}\right]\right)}$ & $\mathrm{W} \mathrm{m}{ }^{-1} \mathrm{~K}^{-1}$ & Thermal conductivity \\
\hline$c_{\mathrm{p}}(T)$ & $152.5+7.122 T\left[\mathrm{~K}^{-1}\right]$ & $\mathrm{J} \mathrm{kg}^{-1} \mathrm{~K}^{-1}$ & Specific heat capacity \\
\hline$z_{\mathrm{sl}}$ & 0 & $\mathrm{~m}$ & Sea level \\
\hline spy & 31536000 & $\mathrm{sa}^{-1}$ & Seconds per year \\
\hline
\end{tabular}

contradiction to the suspicion of the presence of marine sediments. It is important to state that absolute values of roughness cannot be derived from these calculations. It is rather the pattern relating to relative roughness values that is significant.

\section{Experiment description}

\subsection{Experiment 1: reference simulation}

The main difficulty is to capture the distinct surface flow pattern by making appropriate assumptions about the basal sliding behaviour. Many ice modelling studies use a constant set of basal sliding parameters to reproduce somewhat realistic surface velocity fields (e.g. Rückamp, 2011; Kleiner and Humbert, 2014). This approach can not be adopted for PIG, as it leads to a shut down of parts of the fast-flowing main trunk due to very low basal shear stresses in that region (Joughin et al., 2009; Morlighem et al., 2010). Instead, for our reference simulation, an inversion for basal parameters is conducted. This approach will lead to a realistic reproduction of the surface flow velocity field and lets us analyse the thermal structure of the glacier.

The inversion method (cf. Schmeltz et al., 2002) used for our reference simulation starts by assuming the linearised form of Eq. (12): thus $\boldsymbol{\tau}_{\mathrm{b}}=\beta^{2} \boldsymbol{u}_{\mathrm{b}}$, where $\beta^{2}$ is the basal sliding parameter to be inferred. Additionally, a simulation is conducted where the glacier base is not allowed to slide. Therefore the resulting surface velocity field $\boldsymbol{u}_{\text {s,nosl }}$ can be seen to be solely due to internal deformation. The basal slid- ing velocity $\boldsymbol{u}_{\mathrm{b}}$ can be approximated by subtracting the surface velocity due to internal deformation $\boldsymbol{u}_{\mathrm{s} \text {,nosl }}$ from the measured surface velocity field $\boldsymbol{u}_{\text {obs }}$ (Rignot et al., 2011, Fig. 1). The basal drag from the simulation where no basal sliding is allowed, $\boldsymbol{\tau}_{\mathrm{b} \text {,nosl }}$, is taken as a good first representation of the real basal drag distribution, $\boldsymbol{\tau}_{\mathrm{b}}$. With this, the field of the basal sliding parameter $\beta^{2}$ is defined as

$\beta^{2}=\left|\boldsymbol{\tau}_{\mathrm{b}, \operatorname{nosl}}\right|\left(\left|\boldsymbol{u}_{\mathrm{obs}}\right|-\left|\boldsymbol{u}_{\mathrm{s}, \text { nosl }}\right|\right)^{-1}$,

as shown in Fig. 3. This is a significantly different approach from in e.g. Joughin et al. (2009), Morlighem et al. (2010) and Seroussi et al. (2014), who minimise a cost function.

The basal sliding parameter $\beta^{2}$ is subsequently applied in the forward model in the linear sliding law. Since the amount of internal deformation in the ice crucially depends on the ice temperature (Eq. 4), it is important to consider a realistic temperature distribution within the ice. At this point it is important to note that the model is applied in a diagnostic manner and therefore the received temperature distribution is a steady state one for a fixed geometry with constant boundary conditions which might differ from the actual transient field. Nonetheless, the received field is likely to show a better approximation to reality than simply assuming a certain distribution. To consider a realistic temperature distribution within the ice, we conduct the above-described procedure in an iterative manner. We first conduct a "no sliding" simulation nosl, 1 with a constant temperature of $T=263.15 \mathrm{~K}$. The resulting surface velocity field $\boldsymbol{u}_{\mathrm{s}, \text { nosl,1 }}$ and basal drag $\boldsymbol{\tau}_{\mathrm{b}, \text { nosl,1 }}$ lead to a basal sliding parameter $\beta_{1}^{2}$. This basal sliding parameter enters the next simulation step, in which basal sliding $s l, 1$ is accounted for and the temperature field is solved 

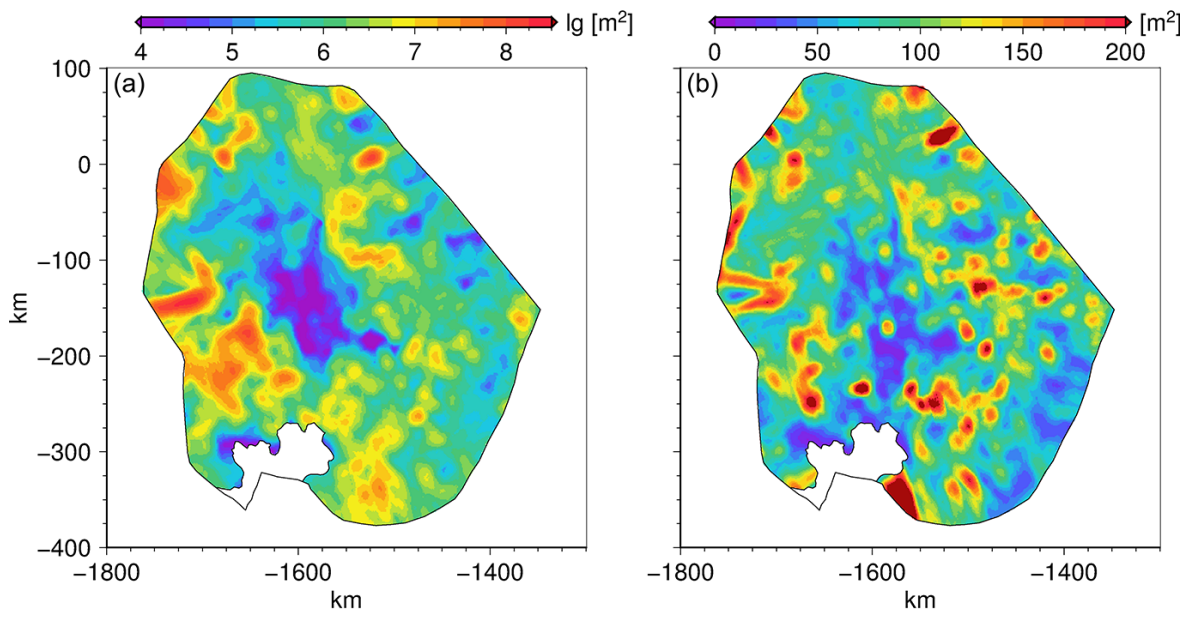

Figure 2. Calculated roughness parameters at Pine Island Glacier, given by the roughness amplitude $\xi$ (a) and the roughness frequency $\eta$ (b).

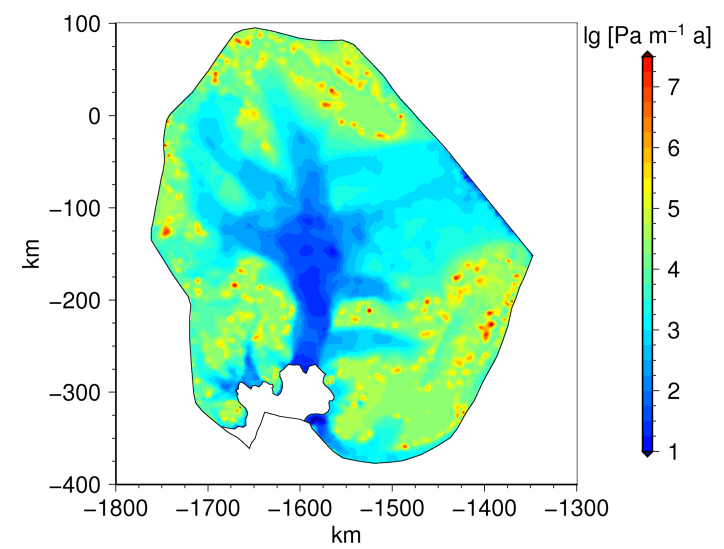

Figure 3. Spatial distribution of the basal sliding parameter $\beta^{2}$.

for. The temperature distribution enters the next "no sliding" simulation nosl, 2 as a constant field. Again a basal sliding parameter is found, entering the next simulation step $s l, 2$, which is our final reference simulation ref. Thus the procedure is stopped after two iterations and listed in a schematic manner as $n o s l, l(T=263.15 \mathrm{~K}) \rightarrow \beta_{1}^{2} \rightarrow s l, l(T$ solved $) \rightarrow$ $n o s l, 2(T$ from $s l, 1) \rightarrow \beta_{2}^{2} \rightarrow s l, 2 / r e f(T$ solved $)$.

The reference simulation serves as a validation parameter for the subsequent experiments. As a quantitative measure the root-mean-square (RMS) deviation $\mathrm{RMS}_{\boldsymbol{u}_{\mathrm{s}}}$ (unit: $\mathrm{m} \mathrm{a}^{-1}$ ) between the simulated surface velocity field $\boldsymbol{u}_{\mathrm{s} \text { sim }}$ and the reference surface velocity field $\boldsymbol{u}_{\mathrm{s}, \text { ref }}$ is given by

$\operatorname{RMS}_{\boldsymbol{u}_{\mathrm{s}}}=\sqrt{\frac{1}{m} \sum_{i=1}^{m}\left(|| \boldsymbol{u}_{\mathrm{s}, \operatorname{sim} \mid i}-\left|\boldsymbol{u}_{\mathrm{s}, \text { ref }}\right|_{i} \mid\right)^{2}}$,

where $m$ is the number of discrete values on a regular grid with $1 \mathrm{~km}$ spacing. The comparison is done in three distinct regions: fast flow velocities ("fast"), slower flow velocities ("slow") and the entire model region ("all") (detailed description in Wilkens, 2014). The regions of all tributaries (114), the central stream (CS) and the shelf area (shelf) are combined to the region "fast", while the remainder is the region "slow" (cf. Fig. 8b and c)

\subsection{Experiment 2: parametrisation with single-parameter roughness}

The approach in the reference simulation is dissatisfying when aiming to constrain basal sliding with physical parameters at the base of the glacier. Therefore, we introduce in this experiment a parametrisation of basal sliding that considers the basal roughness below the glacier in the formulation of the commonly used Weertman-type sliding law (Eq. 12), with the aim of reproducing the surface velocity field of PIG. Instead of inverting for one spatially varying parameter, we now connect the basal sliding parameter $C_{\mathrm{b}}$ to the measured single-parameter roughness measure $\xi$ (Rippin et al., 2011), Sect. 3.4, as it is closest to the original physical meaning of $C_{\mathrm{b}}$.

The absolute values of the roughness measure $\xi$ are dependent on parameters chosen for its derivation (e.g. wavelength interval in Rippin et al., 2011). At the same time the sliding parameter $C_{\mathrm{b}}$ depends not only on mechanical properties, such as basal roughness, but also thermal properties. Therefore, the roughness measure $\xi$ can not directly be used as the sliding parameter. To use the roughness information, we select a range for the sliding parameter $C_{\mathrm{b}}$, obtained via the approximation

$C_{\mathrm{b}}=\frac{\left(\left|\boldsymbol{u}_{\mathrm{obs}}\right|-\left|\boldsymbol{u}_{\mathrm{s}, \text { nosi }}\right|\right) N_{\mathrm{b}}^{q}}{\left|\boldsymbol{\tau}_{\mathrm{b}, \text { nos } 1}\right|^{p}}$.

To obtain a roughness parameter that depends on the roughness measure $\xi$, the resulting range $\left[C_{\mathrm{b}, \min }, C_{\mathrm{b}, \max }\right]$ is mapped onto the range of the roughness measure $\left[\xi_{\min }, \xi_{\mathrm{max}}\right]$, 
such that

$C_{\mathrm{b}}(\xi)=\frac{\left(C_{\mathrm{b}, \max }-C_{\mathrm{b}, \min }\right) \cdot\left(\xi-\xi_{\min }\right)}{\left(\xi_{\min }-\xi_{\max }\right)}+C_{\mathrm{b}, \max }$.

The lowest roughness correlates with the highest basal sliding and therefore the highest values of $C_{b}(\xi)$. In the following we will refer to the basal sliding parameter $C_{\mathrm{b}}(\xi)$ as $C_{\xi}$ when it is related to the basal roughness measure $\xi$.

In total we conduct 15 simulations for Experiment 2, where each parameter combination represents a potential subglacial setting. In all simulations the coefficient $p=1$ is kept constant, while $q$ is varied to investigate the effect of the effective pressure onto the sliding velocities $(q \in\{0,1,2\})$. This results in varying minimum and maximum values for $C_{\xi}$ for each parameter combination. To account for potential outliers in the $C_{\xi}$ distribution, we have subsequently narrowed the range of $C_{\xi}$. This results in varying minimum and maximum values for $C_{\xi}$ for each parameter combination. Hence, simulations with an identifier 1-5 are conducted with $q=0$ and five different ranges of $C_{\xi}$, simulations 6-10 with $q=1$ and five different ranges of $C_{\xi}$ and simulations 11-15 with $q=2$ and five different ranges of $C_{\xi}$. The ranges of $C_{\xi}$ can be found in Table 5.2 in Wilkens (2014).

\subsection{Experiment 3: parametrisation with two-parameter roughness}

The aim of this experiment is to test the idea of Li et al. (2010) for its applicability to PIG. This approach also relates the basal roughness to the basal sliding velocity. This time the roughness is represented by a two-parameter roughness measure for the amplitude $\xi$ and frequency $\eta$ of the undulations. The approach is based on Weertmans original formulation (Weertman, 1957) of describing the sliding mechanisms of regelation and enhanced creep, such that

$\boldsymbol{u}_{\mathrm{b}}=C_{\mathrm{W}}\left(\boldsymbol{\tau}_{\mathrm{b}} \frac{l^{2}}{a^{2}}\right)^{\frac{(1+n)}{2}}$,

where $C_{\mathrm{W}}$ is a parameter defined by thermal and mechanical properties of the ice, $l$ is the obstacle spacing, $a$ is the obstacle size (cf. Weertman, 1957) and $n=3$ is the stress exponent.

Li et al. (2010) state that the two-parameter roughness measures $\xi$ and $\eta$, representing the amplitude and frequency of the roughness (cf. Sect. 3.4), can be used as a proxy for the vertical and horizontal length scales present at the base due to their statistical meanings, such that $a=c_{1} \sqrt{\xi}$ and $l=c_{2} \sqrt{\eta}$, where $c_{1}$ and $c_{2}$ are proportionality factors.

Entering this into Weertmans original formulation (Eq. 23) and additionally including a temperature function $f(T)$ as introduced above leads to

$\boldsymbol{u}_{\mathrm{b}}=C_{\mathrm{L}} f(T)\left(\boldsymbol{\tau}_{\mathrm{b}} \frac{\eta}{\xi}\right)^{\frac{(n+1)}{2}}$ with the constant $C_{\mathrm{L}}=C_{\mathrm{W}}\left(c_{2} / c_{1}\right)^{1+n}$. As the proportionality factors $c_{1}$ and $c_{2}$ are not further defined, we take $C_{\mathrm{L}}$ as a single parameter to adjust.

The upper and lower bounds for $C_{\mathrm{L}}$ are obtained via

$C_{\mathrm{L}}=\left(\left|\boldsymbol{u}_{\text {obs }}\right|-\left|\boldsymbol{u}_{\mathrm{s}, \text { nosl }}\right|\right)\left|\boldsymbol{\tau}_{\mathrm{b}, \text { nosl }}\right|^{-\frac{(n+1)}{2}}\left(\frac{\xi}{\eta}\right)^{\frac{(n+1)}{2}}$.

The vast majority of the values lie within $C_{\mathrm{L}}=\left[3 \times 10^{-2} ; 3 \times\right.$ $\left.10^{2}\right] \mathrm{Pa}^{-2} \mathrm{~m} \mathrm{a}^{-1}$. We conduct 18 simulations for this experiment, whereby the value of $C_{\mathrm{L}}$ (Eq. 24) is varied in this range.

For all simulations conducted for Experiment 3, only Eq. (2) is solved for due to time constraints (cf. Wilkens, 2014). The temperature distribution within the ice is taken from the reference simulation. Use of the temperature field from the reference simulation gives the opportunity to connect the sliding behaviour to the basal temperature, thus only allowing ice to slide where $T$ is close to $T_{\mathrm{pmp}}$.

\section{Results}

\subsection{Experiment 1}

The resulting surface velocity field from the reference simulation is shown in Fig. 4. The general pattern of the surface velocity field is well reproduced in the reference simulation compared to the observed surface velocity field (Fig. 1). The tributaries are all in the right location and the velocity magnitudes agree in most areas well. The highest differences between $\left|\boldsymbol{u}_{\mathrm{s} \text {,ref }}\right|$ and $\left|\boldsymbol{u}_{\text {obs }}\right|$ are found in the ice shelf, where the simulated velocities are up to $1 \mathrm{~km} \mathrm{a}^{-1}$ smaller than the observed ones.

When solely looking at the velocity magnitudes we again find that for higher velocities the simulated velocity field is lower than the observed field (Fig. 5). The spread around the diagonal for lower velocities appears bigger, which is mainly due to the logarithmic axes chosen. For higher flow velocities the direction of flow of the simulated field agrees well with the direction of the observed field. This is shown as a colour code for the angle offset between the velocity vectors in Fig. 5. For slower velocities the angle offset is bigger, coinciding with a higher measurement error for slower velocities.

The simulation shows that large areas under PIG are temperate (Fig. 6). In general the overall flow pattern is reflected in the basal temperature structure, with fast-flowing areas being underlain by a temperate base. Figure 7 shows the homologous temperature $T_{\text {ref }}^{\prime}$ at three vertical slices, of which the locations are indicated in Fig. 6. The slice located furthest away from the ice shelf shows that the base is mainly temperate, while the inner ice body (away from the base) is predominantly cold (Fig. 7a). A similar picture is found in the next slice, which is located further downstream towards the ice shelf (Fig. 7b). Here, additionally a cold core can be seen, located in the fast-flowing central stream. 


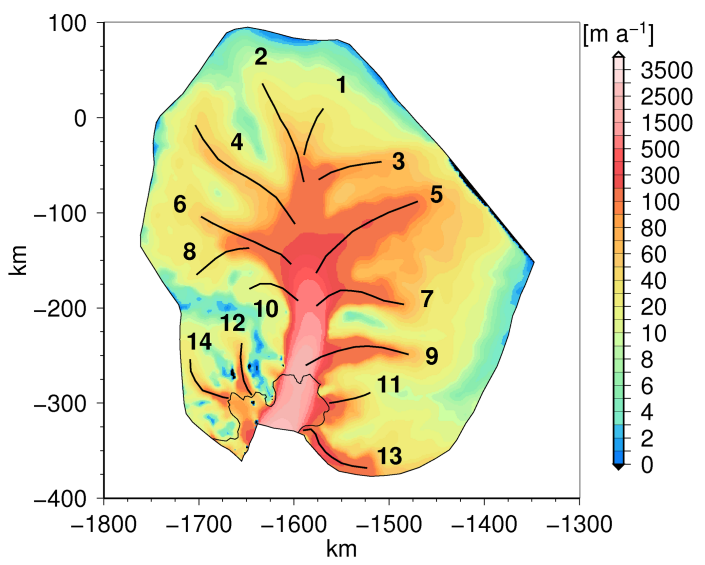

Figure 4. Surface velocity field from the reference simulation $\left|\boldsymbol{u}_{\mathrm{s}, \text { ref }}\right|$ with the numbered tributaries.

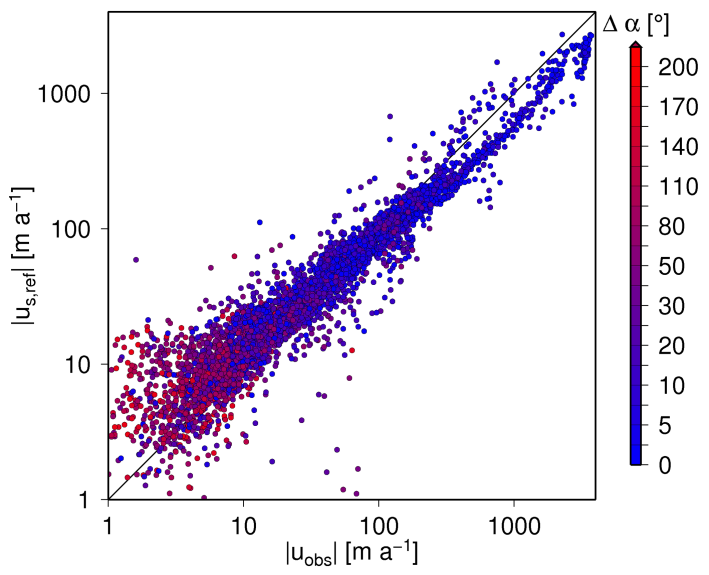

Figure 5. Observed surface velocity field $\left|\boldsymbol{u}_{\text {obs }}\right|$ versus reference surface velocity field $\left|\boldsymbol{u}_{\mathrm{s} \text {,ref }}\right|$. The logarithmic scales exaggerate the spread around the low speeds. The angle offset $\Delta \alpha$ between the vectors of the surface velocity field $\boldsymbol{u}_{\mathrm{obs}}$ and the reference surface velocity field $\boldsymbol{u}_{\mathrm{s} \text {,ref }}$ is shown as the colour code.

The next slice partly crosses the ice shelf (Fig. 7c). It can be well observed that a cold core is entering the ice shelf. In the vicinity of tributary 11 (cf. Fig. 1) a small temperate layer is found.

\subsection{Experiment 2}

We show in Fig. 8a the RMS $\boldsymbol{u}_{\mathrm{s}}$ deviations between the reference simulation and Experiment 2 for all 15 conducted parameter combinations. It can be seen, that the "fast" regions differ most for all parameter combinations tested here. Additionally, for the entire region "all" there seems to be no single parameter combination that minimises the $\mathrm{RMS}_{\boldsymbol{u}_{\mathrm{S}}}$ value. Although the RMS is relatively high, some of the complex surface flow features could be reproduced with our approach, which can only be seen by looking at the qualitative structure of the resulting surface flow fields. Fig. 8b shows the surface

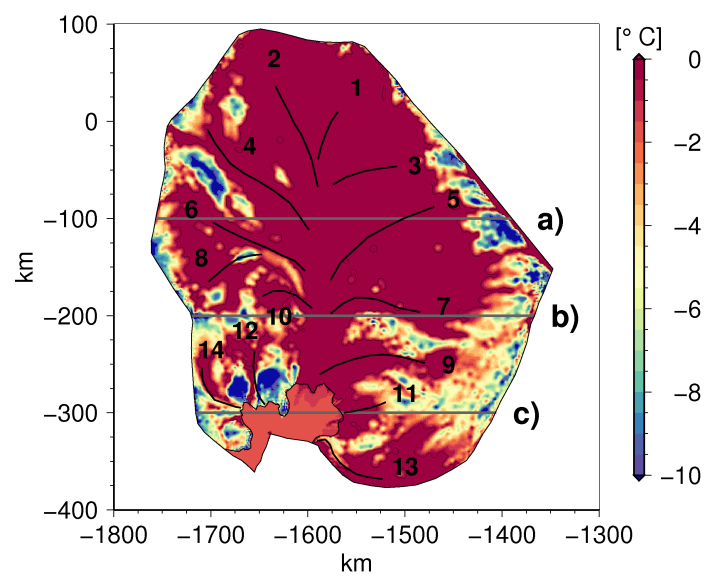

Figure 6. The basal homologous temperature from the reference simulation $T_{\mathrm{b}, \text { ref }}^{\prime}$, with tributary locations in black and the location of the vertical slices (a), (b) and (c) in Fig. 7 in grey.

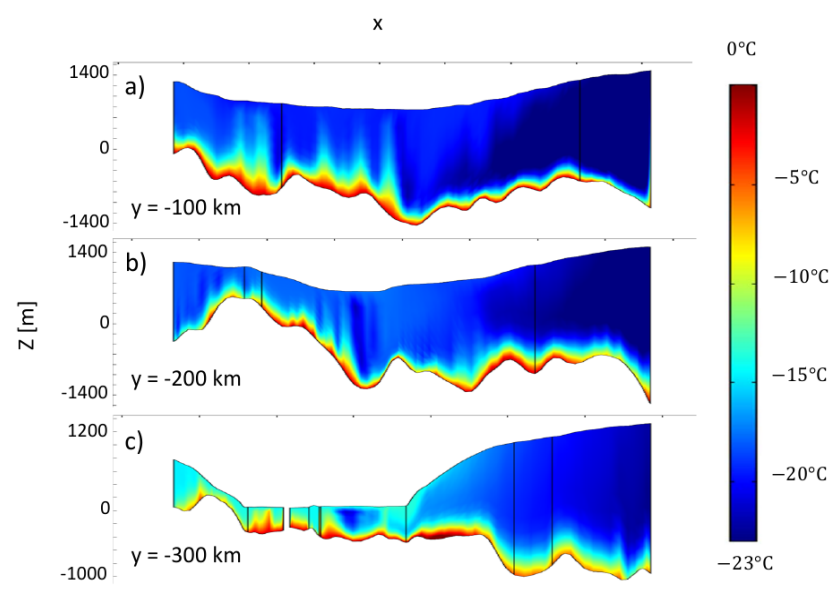

Figure 7. The internal homologous temperature from the reference simulation $T_{\text {ref }}^{\prime}$ at three vertical slices (a), (b) and (c) (horizontal locations indicated in Fig. 6).

velocity field with $q=0$, which means the effect of the effective pressure is cancelled out (simulation identifier 2). The location of tributary 7 (and slightly 11) and the central stream are well reproduced.

Although the central stream is in general well reproduced, the inflow into the ice shelf is characterized by a drop of flow velocities which does not coincide with the observed velocities. In the simulations where the effective pressure is considered with $q=2$ (simulation identifiers 11-15), a much better representation of the central stream at the inflow into the ice shelf across the grounding line is found, as can be seen for example in the surface flow field from Simulation 11 shown in Fig. 8c. The influence of the effective pressure $N_{\mathrm{b}}$ is thus emphasised. At the same time, this method does not lead to a full reproduction of the surface flow structure. This suggests that other processes not considered here may also be important for the basal sliding behaviour. A possibility, not 

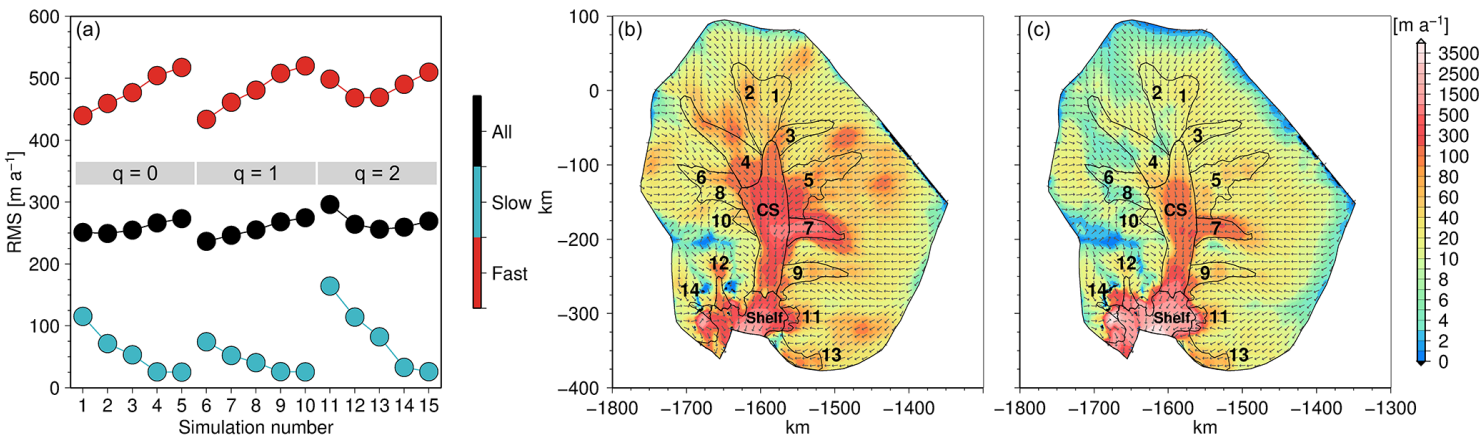

Figure 8. (a) RMS error to the surface velocity field of the reference simulation versus the simulation number; (b) surface velocity field of Simulation 2 with $q=0$; (c) surface velocity field of Simulation 11 with $q=2$.

tested yet due to cpu time constraints (for a detailed description of the solution time of the simulations refer to Wilkens, 2014), is the effect of the basal stress exponent $p$. Increasing it would possibly regulate to some extent the high velocities in some areas due to low basal stresses.

The basal homologous temperature from Simulation 2 (Fig. 9) shows a very clear structure of the temperate base below the tributaries, even though they are not clearly visible in the flow field (cf. Fig. 8b). The temperature-driven separation between tributaries 2 and 4 and tributaries 7 and 9 is even more visible than in the reference simulation (cf. Fig. 6). The structure of the basal homologous temperature of all other simulations looks very similar to that of Simulation 2, but the total area fraction of ice at pressure melting point, as well as the separation between the tributaries, varies.

Another interesting feature found in the structure of the basal temperature from Simulation 2 is the advection of warmer ice into the shelf. This feature can be attributed to the implementation of the thermal basal boundary condition in the shelf (cf. Sect. 2.3). While the heat flux is not allowed to raise the temperature above $271.15 \mathrm{~K}$, it does not hinder the advection of warmer ice from the grounded areas. The structure of the bands of warmer ice agree well with melt channels below the ice shelf, as found by Vaughan et al. (2012).

\subsection{Experiment 3}

The RMS $\boldsymbol{u}_{\boldsymbol{u}_{\mathrm{s}}}$ deviations between the reference simulation and all conducted parameter combinations in Experiment 3 show a somewhat regular pattern (Fig. 10a). For the slower-flowing areas, the RMS $\boldsymbol{u}_{\boldsymbol{u}_{\mathrm{s}}}$ value increases with increasing $C_{\mathrm{L}}$. For the faster-flowing areas, the $\mathrm{RMS}_{\boldsymbol{u}_{\mathrm{s}}}$ value first slightly decreases with increasing $C_{\mathrm{L}}$ and, after reaching a minimum of $\mathrm{RMS}_{\boldsymbol{u}_{\mathrm{s}}}=500 \mathrm{~m} \mathrm{a}^{-1}$ for $C_{\mathrm{L}}=1.58 \mathrm{~Pa}^{-2} \mathrm{~m} \mathrm{a}^{-1}$, increases with increasing $C_{\mathrm{L}}$. Since we conduct simulations with discrete values for $C_{\mathrm{L}}$, the value of $\mathrm{RMS}_{\boldsymbol{u}_{\mathrm{s}}}=500 \mathrm{~m} \mathrm{a}^{-1}$ represents the minimum value for the simulations conducted here and not an absolute minimum. The RMS $\boldsymbol{u}_{\mathrm{s}}$ value for the entire region "all" shows a similar behaviour of first decreas-

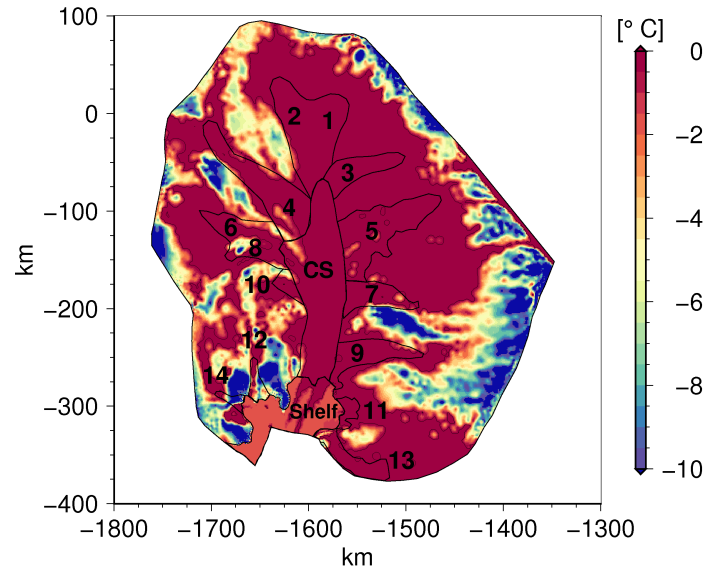

Figure 9. Basal homologous temperature of Simulation 2.

ing and then increasing with increasing $C_{\mathrm{L}}$, with a minimum $\mathrm{RMS}_{\boldsymbol{u}_{\mathrm{s}}}$ value of $271 \mathrm{~m} \mathrm{a}^{-1}$ for $C_{\mathrm{L}}=1 \mathrm{~Pa}^{-2} \mathrm{~m} \mathrm{a}^{-1}$.

Although RMS values reveal a slight minimum, the surface velocity field of PIG is not reproduced with all its features. For higher $C_{\mathrm{L}}$ values that reproduce the velocities in the central stream in a better manner, the velocities in the slower-flowing area around tributaries 3, 5, 7 and 9, located to the south of the main stream, are simulated much too high.

A striking feature of all simulations is that the central stream is partitioned into a faster-flowing upper part and a slower-flowing lower part in the vicinity of the ice shelf. We show an example for a $C_{\mathrm{L}}$ value with a low RMS value and a $C_{\mathrm{L}}$ value with a high RMS value (Fig. $10 \mathrm{~b}$ and c). However, when looking at the structure of the surface flow fields it is apparent that some features of the observed surface flow field are reproduced.

Additionally, the area around tributary 14 behaves slightly different to most other tributaries. It speeds up much faster for much lower values of $C_{\mathrm{L}}$. This is related to the low roughness measures $\xi$ and $\eta$ in that region. 

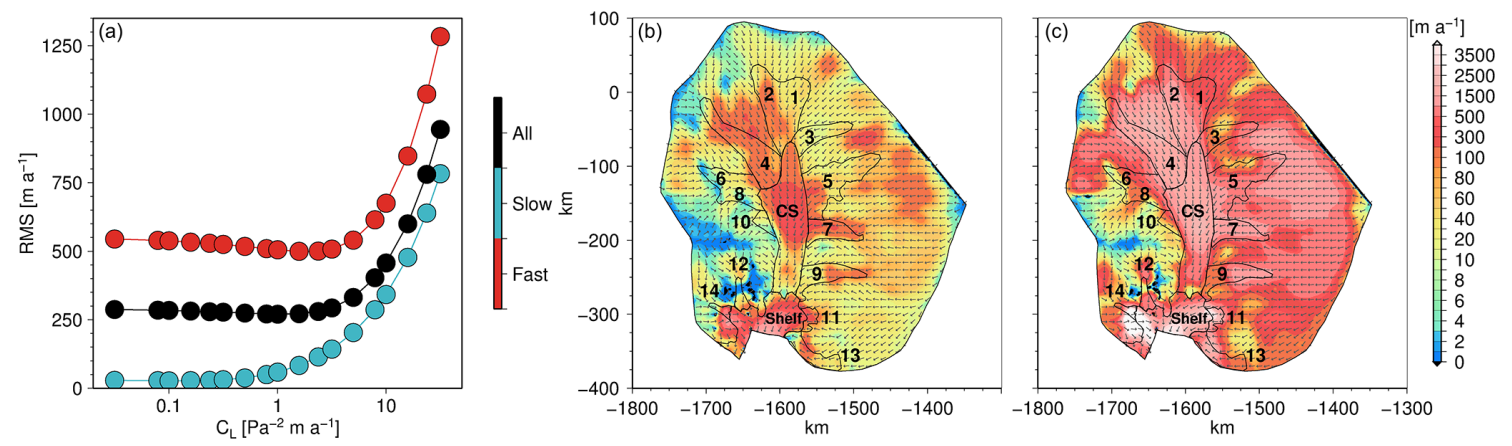

Figure 10. (a) RMS error to the surface velocity field of the reference simulation versus $C_{\mathrm{L}}$ value; (b) surface velocity field with $C_{\mathrm{L}}=$ $1 \mathrm{~Pa}^{-2} \mathrm{ma}^{-1}$; (c) surface velocity field with $C_{\mathrm{L}}=31.56 \mathrm{~Pa}^{-2} \mathrm{~m} \mathrm{a}^{-1}$.

\section{Discussion}

We have shown that the complex surface flow structure of PIG could be well reproduced with our simplified approach of an inversion for a basal sliding parameter $\beta^{2}$ in the reference simulation. Although the simulated flow pattern agrees well with observations, some differences in the magnitude of the surface flow velocities to observations were found. These differences are highest in the ice shelf and might be partly related to a slower inflow from the grounded areas where the difference is about $1 \mathrm{~km} \mathrm{a}^{-1}$. This might be due to the position of the grounding line in our model which is further downstream than the location in 2009 to which the observed surface velocity field belongs (2007-2009). As we run the flow model in a diagnostic manner without a relaxation of the geometry, the simulated ice flow could not be consistent with the geometry. Alternatively, it might be caused by the simplified method of inferring $\beta^{2}$, as $\tau_{\mathrm{b}, \text { nosl }}$ is not vanishing near the grounding line as would be expected (cf. Joughin et al., 2010 and Morlighem et al., 2010).

However, the main cause seems to be that we did not account for the highly rifted shear margins. These shear margins have been shown to be rheologically softer than undamaged ice (e.g. Humbert et al., 2009). In reality the shear margins partly uncouple the fast-flowing central part from the surrounding ice. In our study we neglect the effect of shear margins and treat them as rheologically equal to undamaged ice. This leads to an overestimation of the flow outside the central stream and an underestimation within the central stream in the main trunk. The softening due to shear margins can be included in different ways, as for example done in Joughin et al. (2010) and Favier et al. (2014).

From the simulated temperature distribution we found that the base of the glacier is predominantly temperate with the absence of a significant temperate layer; the rest of the inner ice body is mainly cold. This finding is consistent with the general definition of an Antarctic glacier where, due to cold conditions at the surface, the cold-temperate transition surface (Blatter and Hutter, 1991) is located at or near the base. To form a significant basal temperate layer, Blatter and
Hutter (1991) state that strain heating is the necessary mechanism. This also agrees well with our results, as the flow of PIG is dominated by basal sliding, and therefore strain heating due to internal deformation is small. Only an area around tributary 11 (cf. Figs. 6 and 7c), where strain heating is much higher, shows the existence of a somewhat larger temperate layer at the base. Unfortunately there are no measured (deep) ice core temperatures available at PIG to which our results could be compared. Nonetheless, our findings of a temperate base below some parts of PIG are supported by findings from Smith et al. (2013) of the existence of water below the glacier.

As the first new parametrisation for basal sliding we tested the applicability of including actual measured roughness data in the commonly used Weertman-type sliding law. The new parameter $C_{\xi}$ was applied in the basal sliding law and we were able to reproduce many of the tributaries, although not the full complexity of the flow structure. For instance, the central stream is in large areas underlain by a very smooth bed, indicated by a low roughness measure $\xi$, which becomes rougher towards the grounding line.

We have shown that the influence of the effective pressure onto basal sliding must be large close to the grounding line to keep the flow velocities high. As part of the overburden pressure is supported by the basal water of the marine setting of the glacier, the effective pressure is low and basal motion is therefore facilitated.

The locations of the fast-flowing tributaries and the central stream are well indicated by a temperate base. The structure is visible even more clearly than for the reference simulation. This supports the idea that the location of some tributaries is influenced by basal temperatures.

A full reproduction of the surface flow structure is not achieved with the single-parameter roughness measure. This suggests that other processes, not considered here, are also important for the basal sliding behaviour. In addition, the basal stress exponent $p$ would, to some extent, perhaps regulate the high velocities in some areas due to low basal 
stresses. The effect of $p$ on the flow field has not been investigated here but should be considered in the future.

For the second new parametrisation for basal sliding we test the applicability of a theory developed by Li et al. (2010) to the region of PIG that connects a two-parameter roughness measure $\{\xi, \eta\}$ to the basal sliding law. This approach additionally accounts for the frequency of roughness but neglects the effective pressure. The results of the surface flow field show that the central stream in all the simulations from this experiment is partitioned into a faster-flowing upper part and a slower-flowing lower part in the vicinity of the ice shelf. No single value for $C_{\mathrm{L}}$ could be found that reproduces the surface velocity field of PIG with all its features. To account for the frequency roughness does not lead to an overall better representation of the flow compared to the single-parameter approach. We expect that if the effective pressure at the base is considered in the sliding formulation of Li et al. (2010), the results would significantly improve as the reduced effective pressure at the grounding line in the marine setting of PIG would favour higher sliding velocities.

Despite the inability to completely reproduce the surface flow field of PIG with the methods using the roughness measure, this approach represents some important flow features, like the location of the fast-flowing central stream and some of the numerous tributaries.

To derive basal properties and to adjust basal sliding parameters, pure inversion methods use the observed velocity field and minimise the misfit between observation and model results. They require no or only very little information about the bedrock properties (e.g. bed type, temperature or availability of basal water) and result in a very good representation of the flow for the time of observation. The derived basal sliding parameters then contain not only processes related to sliding but all assumptions and approximations of the applied flow model, as the surface flow is a superposition of ice deformation and basal motion. Inversion methods are therefore not sufficient to gain the knowledge about the processes at the base and their complex interplay.

In comparison to the inversion methods our approach relates sliding to the physical parameter of the subglacial bed roughness. Although the measured bed roughness is only valid for a certain period as the subglacial environment changes over time, we do not expect the main features to change in the near future. One important process for prognostic simulations over longer timescales could be basal erosion (Smith et al. (2012) report relatively high erosion rates at PIG of $0.6 \mathrm{~m} \mathrm{a}^{-1} \pm 0.3 \mathrm{~m} \mathrm{a}^{-1}$ ), but this is beyond the scope of this work.

In this study the effective pressure at the base is only influenced by the height above buoyancy and affects only the areas below sea level. This is a strong restriction of the model as the sliding formulation is not connected to the very diverse hydrology at the base of the glacier. A sufficiently complex/realistic hydrology model would be a great benefit for this and for every other ice flow model. In that case, it might be beneficial to separate the hydrology component from the sliding relation. However, this is beyond the scope of this work.

\section{Conclusions}

The overall motion of the fast-flowing parts of PIG are dominated by basal motion. The parametrisation of basal motion is therefore crucial for simulating the flow of PIG. Especially when running prognostic simulations of the glacier and aiming at analysing the stability of the system, parametrisation of basal motion is important. We introduce two different approaches for connecting a basal sliding formulation to an actually measurable subglacial parameter, the basal roughness measure. Our results show that the roughness measure is a very useful parameter to be considered for parametrisation of basal motion at PIG because important features of the flow field could be reproduced. Nonetheless the full complexity of the problem was not captured. Our approach is a step towards a more physically based parametrisation for basal sliding, which is very important for realistic simulations of glacier dynamics.

Acknowledgements. This work was supported through the Cluster of Excellence "CliSAP" (EXC177), University of Hamburg, funded by the German Science Foundation (DFG). We would like to thank Anne Le Brocq for providing the compiled data set for the geometry of Pine Island Glacier. We thank Stephen Cornford, an anonymous referee and the editor, Olivier Gagliardini, for their very helpful suggestions which improved the manuscript.

Edited by: O. Gagliardini

\section{References}

Aschwanden, A. and Blatter, H.: Mathematical modeling and numerical simulation of polythermal glaciers, J. Geophys. Res.Earth, 114, F01027, doi:10.1029/2008JF001028, 2009.

Bamber, J. L., Gomez-Dans, J. L., and Griggs, J. A.: A new 1 km digital elevation model of the Antarctic derived from combined satellite radar and laser data - Part 1: Data and methods, The Cryosphere, 3, 101-111, doi:10.5194/tc-3-101-2009, 2009.

Bindschadler, R.: The importance of pressurized subglacial water in separation and sliding at the glacier bed, J. Glaciol., 29, 3-19, 1983.

Bingham, R. and Siegert, M.: Quantifying subglacial bed roughness in Antarctica: implications for ice-sheet dynamics and history, Quaternary Sci. Rev., 28, 223-236, 2009.

Bingham, R. G. and Siegert, M. J.: Radar-derived bed roughness characterization of Institute and Möller ice streams, West Antarctica, and comparison with Siple Coast ice streams, Geophys. Res. Lett., 34, L21504, doi:10.1029/2007GL031483, 2007.

Bingham, R. G., Siegert, M. J., Young, D. A., and Blankenship, D. D.: Organized flow from the South Pole to the Filchner-Ronne ice shelf: An assessment of balance velocities in interior East 
Antarctica using radio echo sounding data, J. Geophys. Res.Earth, 112, F03S26, doi:10.1029/2006JF000556, 2007.

Blatter, H. and Hutter, K.: Polythermal conditions in Arctic glaciers, J. Glaciol., 37, 261-269, 1991.

Bohlander, J. and Scambos, T.: Antarctic coastlines and grounding line derived from MODIS Mosaic of Antarctica (MOA), National Snow and Ice Data Center, Digital media (last access: 24 April 2008), Boulder, Colorado, USA, 2007.

Budd, W. and Jenssen, D.: Numerical modelling of the large-scale basal water flux under the West Antarctic Ice Sheet, in: Dynamics of the West Antarctic Ice Sheet, edited by: Van der Veen, C. J. and Oerlemans, J., 293-320, Kluwer, Dordrecht, 1987.

Codina, R.: Comparison of some finite element methods for solving the diffusion-convection-reaction equation, Comput. Method. Appl. M., 156, 185-210, doi:10.1016/S0045-7825(97)00206-5, 1998.

Comiso, J.: Variability and Trends in Antarctic surface temperatures from in situ and satellite infrared measurements, J. Climate, 13, 1674-1696, 2000.

COMSOL: COMSOL Multiphysics Reference Guide, COMSOL $\mathrm{AB}$, Vers. 4.3a, available at: http://www.comsol.com/ (last access: 10 August 2014), 2012.

Cornford, S., Martin, D., Graves, D., Ranken, D., Le Brocq, A., Gladstone, R., Payne, A., Ng, E., and Lipscomb, W.: Adaptive mesh, finite volume modeling of marine ice sheets, J. Comput. Phys., 232, 529-549, 2012.

Cuffey, K. M. and Paterson, W. S. B.: The Physics of Glaciers, Butterworth-Heinemann, Oxford, UK, 4th edn., 2010.

Dutrieux, P., De Rydt, J., Jenkins, A., Holland, P., Ha, H., Lee, S., Steig, E., Ding, Q., Abrahamsen, E., and Schröder, M.: Strong sensitivity of Pine Island ice-shelf melting to climatic variability, Science, 343, 174-178, 2014.

Favier, L., Durand, G., Cornford, S., Gudmundsson, G., Gagliardini, O., Gillet-Chaulet, F., Zwinger, T., Payne, A., and Le Brocq, A.: Retreat of Pine Island Glacier controlled by marine ice-sheet instability, Nature Climate Change, 4, 117-121, doi:10.1038/NCLIMATE2094, 2014.

Fowler, A.: A sliding law for glaciers of constant viscosity in the presence of subglacial cavitation, P. R. Soc. A, 407, 147-170, 1986.

Fox Maule, C., Purucker, M., Olsen, N., and Mosegaard, K.: Heat flux anomalies in Antarctica revealed by satellite magnetic data, Science, 309, 464-467, 2005.

Gladstone, R., Lee, V., Rougier, J., Payne, A., Hellmer, H., Brocq, A. L., Shepherd, A., Edwards, T., Gregory, J., and Cornford, S.: Calibrated prediction of Pine Island Glacier retreat during the 21st and 22nd centuries with a coupled flowline model, Earth Planet. Sc. Lett., 333-334, 191-199, 2012.

Glen, J.: The creep of polycrystalline ice, P. R. Soc. A., 228, 519538, 1955.

Greve, R. and Blatter, H.: Dynamics of Ice Sheets and Glaciers, Springer, Berlin, Heidelberg, 2009.

Gudmundsson, G. H., Krug, J., Durand, G., Favier, L., and Gagliardini, O.: The stability of grounding lines on retrograde slopes, The Cryosphere, 6, 1497-1505, doi:10.5194/tc-6-1497-2012, 2012.

Hauke, G. and Hughes, T. J.: A comparative study of different sets of variables for solving compressible and incompressible flows,
Comput. Method. Appl. M., 153, 1-44, doi:10.1016/S00457825(97)00043-1, 1998.

Helm, V., Humbert, A., and Miller, H.: Elevation and elevation change of Greenland and Antarctica derived from CryoSat2, The Cryosphere, 8, 1539-1559, doi:10.5194/tc-8-1539-2014, 2014.

Hooke, R. L.: Principles of Glacier Mechanics, Cambridge University Press, Cambridge, 2005.

Horwath, M. and Dietrich, R.: Signal and error in mass change inferences from GRACE: the case of Antarctica, Geophys. J. Int., 177, 849-864, 2009.

Hubbard, B., Siegert, M., and McCarroll, D.: Spectral roughness of glaciated bedrock geomorphic surfaces: implications for glacier sliding, J. Geophys. Res., 105, 21 295-21 303, 2000.

Hughes, T.: Is the West Antarctic ice sheet disintegrating?, J. Geophys. Res., 78, 7884-7910, 1973.

Humbert, A., Kleiner, T., Mohrholz, C., Oelke, C., Greve, R., and Lange, M.: A comparative modeling study of the Brunt Ice Shelf/Stancomb-Wills Ice Tongue system, East Antarctica, J. Glaciol., 55, 53-65, 2009.

Hutter, K.: Theoretical glaciology: Material Science of Ice and the Mechanics of Glaciers and Ice Sheets, Reidel, Tokyo, 1983.

Huybrechts, P.: The Antarctic ice sheet and environmental change: a three-dimensional modelling study, Reports Polar Res., Alfred Wegener Institute for Polar and Marine Research, Bremerhaven, 99, 1992.

Joughin, I., Tulaczyk, S., Bamber, J., Blankenship, D., Holt, J., Scambos, T., and Vaughan, D.: Basal conditions for Pine Island and Thwaites Glaciers, West Antarctica, determined using satellite and airborne data, J. Glaciol., 55, 245-257, 2009.

Joughin, I., Smith, B., and Holland, D.: Sensitivity of 21st century sea level to ocean-induced thinning of Pine Island Glacier, Antarctica, Geophys. Res. Lett., 37, L20502, doi:10.1029/2010GL044819, 2010.

Kamb, B.: Sliding motion of glaciers: theory and observations, Rev. Geophys. Space Phys., 8, 673-728, 1970.

Karlsson, N., Rippin, D., Vaughan, D., and Corr, H.: The internal layering of Pine Island Glacier, West Antarctica, from airborne radar-sounding data, Ann. Glaciol, 50, 141-146, 2009.

Katz, R. and Worster, M.: Stability of ice-sheet grounding lines, P. R. Soc. A., 466, 1597-1620, 2010.

Kleiner, T. and Humbert, A.: Numerical simulations of major ice streams in western Dronning Maud Land, Antarctica, under wet and dry basal conditions, J. Glaciol., 60, 215-232, 2014.

Le Brocq, A. M., Payne, A. J., and Vieli, A.: An improved Antarctic dataset for high resolution numerical ice sheet models (ALBMAP v1), Earth Syst. Sci. Data, 2, 247-260, doi:10.5194/essd-2-247-2010, 2010.

Leguy, G. R., Asay-Davis, X. S., and Lipscomb, W. H.: Parameterization of basal friction near grounding lines in a one-dimensional ice sheet model, The Cryosphere, 8, 1239-1259, doi:10.5194/tc8-1239-2014, 2014.

Li, X., Sun, B., Siegert, M., Bingham, R., Tang, X., Zhang, D., Cui, X., and Zhang, X.: Characterization of subglacial landscapes by a two-parameter roughness index, J. Glaciol., 56, 831-836, 2010.

MacAyeal, D.: The basal stress distribution of Ice Stream E, Antarctica, inferred by control methods, J. Geophys. Res., 97, 595-603, 1992. 
Morland, L.: Thermomechanical balances of ice sheet flows, Geophys. Astro. Fluid., 29, 237-266, 1984.

Morlighem, M., Rignot, E., Seroussi, H., Larour, E., Ben Dhia, H., and Aubry, D.: Spatial patterns of basal drag inferred using control methods from a full-Stokes and simpler models for Pine Island Glacier, West Antarctica, Geophys. Res. Lett., 37, L14502, doi:10.1029/2010GL043853, 2010.

Mouginot, J., Rignot, E., and Scheuchl, B.: Sustained increase in ice discharge from the Amundsen Sea Embayment, West Antarctica, from 1973 to 2013, Geophys. Res. Lett., 41, 1576-1584, doi:10.1002/2013GL059069, 2014.

Nye, J.: The distribution of stress and velocity in glaciers and icesheets, P. R. Soc. A., 239, 113-133, 1957.

Nye, J.: The calculation of sliding of ice over a wavy surface using Newtonian viscous approximation, P. R. Soc. A., A311, 445467, 1969.

Park, J., Gourmelen, N., Shepherd, A., Kim, S., Vaughan, D., and Wingham, D.: Sustained retreat of the Pine Island Glacier, Geophys. Res. Lett., 40, 1-6, 2013.

Paterson, W.: The Physics of Glaciers, Elsevier, Oxford, 1994.

Pattyn, F.: A new three-dimensional higher-order thermomechanical ice sheet model: basic sensitivity, ice stream development, and ice flow across subglacial lakes, J. Geophys. Res., 108, 2382, doi:10.1029/2002JB002329, 2003.

Pattyn, F., Perichon, L., Aschwanden, A., Breuer, B., de Smedt, B., Gagliardini, O., Gudmundsson, G. H., Hindmarsh, R. C. A., Hubbard, A., Johnson, J. V., Kleiner, T., Konovalov, Y., Martin, C., Payne, A. J., Pollard, D., Price, S., Rückamp, M., Saito, F., Souc ${ }^{\mathrm{ek}}$, O., Sugiyama, S., and Zwinger, T.: Benchmark experiments for higher-order and full-Stokes ice sheet models (ISMIPHOM), The Cryosphere, 2, 95-108, doi:10.5194/tc-2-95-2008, 2008.

Pattyn, F., Perichon, L., Durand, G., Favier, L., Gagliardini, O., Hindmarsh, R. C., Zwinger, T., Albrecht, T., Cornford, S., Docquier, D., Fürst, J., Goldberg, D., Gudmundsson, H., Humbert, A., Hutten, M., Huybrechts, P., Jouvet, G., Kleiner, T., Larour, E., Martin, D., Morlighem, M., Payne, A., Pollard, D., Rückamp, M., Rybak, O., Seroussi, H., Thoma, M., and Wilkens, N.: Grounding-line migration in plan-view marine ice-sheet models: results of the ice2sea MISMIP3d intercomparison, J. Glaciol., 59, 2163, doi:10.3189/2013JoG12J129, 2013.

Rignot, E.: Fast recession of a West Antarctic glacier, Science, 281, 549-551, 1998.

Rignot, E.: Ice-shelf changes in Pine Island Bay, Antarctica, 19472000, J. Glaciol., 48, 247-256, 2002.

Rignot, E.: Changes in West Antarctic ice stream dynamics observed with ALOS PALSAR data, Geophys. Res. Lett., 35, L12505, doi:10.1029/2008GL033365, 2008.

Rignot, E., Mouginot, J., and Scheuchl, B.: Ice flow of the Antarctic ice sheet, Science, 333, 1427-1430, 2011.

Rippin, D., Vaughan, D., and Corr, H.: The basal roughness of Pine Island Glacier, West Antarctica, J. Glaciol., 57, 67-76, 2011.

Rippin, D., Bingham, R., Jordan, T., Wright, A., Ross, N., Corr, H., Ferraccioli, F., Brocq, A. L., Rose, K., and Siegert, M.: Basal roughness of the Institute and Moller Ice Streams, West Antarctica: Process determination and landscape interpretation, Geomorphology, 214, 139-147, doi:10.1016/j.geomorph.2014.01.021, 2014.
Rückamp, M.: Eisgeometrie und Fließdynamik der subpolaren Eiskappe von King George Island (Antarktis), Ph.D. thesis, Universität Münster, Münster, 2011.

Schmeltz, M., Rignot, E., Dupont, T., and MacAyeal, D.: Sensitivity of Pine Island Glacier, West Antarctica, to changes in ice-shelf and basal conditions: a model study, J. Glaciol., 48, 552-558, 2002.

Seroussi, H., Morlighem, M., Rignot, E., Mouginot, J., Larour, E., Schodlok, M., and Khazendar, A.: Sensitivity of the dynamics of Pine Island Glacier, West Antarctica, to climate forcing for the next 50 years, The Cryosphere, 8, 1699-1710, doi:10.5194/tc-81699-2014, 2014.

Shepherd, A., Ivins, E. R., A, G., Barletta, V. R., Bentley, M. J., Bettadpur, S., Briggs, K. H., Bromwich, D. H., Forsberg, R., Galin, N., Horwath, M., Jacobs, S., Joughin, I., King, M. A., Lenaerts, J. T. M., Li, J., Ligtenberg, S. R. M., Luckman, A., Luthcke, S. B., McMillan, M., Meister, R., Milne, G., Mouginot, J., Muir, A., Nicolas, J. P., Paden, J., Payne, A. J., Pritchard, H., Rignot, E., Rott, H., Sandberg Sørensen, L., Scambos, T. A., Scheuchl, B., Schrama, E. J. O., Smith, B., Sundal, A. V., van Angelen, J. H., van de Berg, W. J., van den Broeke, M. R., Vaughan, D. G., Velicogna, I., Wahr, J., Whitehouse, P. L., Wingham, D. J., Yi, D., Young, D., and Zwally, H. J.: A reconciled estimate of ice-sheet mass balance, Science, 338, 1183-1189, 2012.

Siegert, M. J., Taylor, J., Payne, A. J., and Hubbard, B.: Macro-scale bed roughness of the siple coast ice streams in West Antarctica, Earth Surf. Proc. Land., 29, 1591-1596, doi:10.1002/esp.1100, 2004.

Siegert, M. J., Taylor, J., and Payne, A. J.: Spectral roughness of subglacial topography and implications for former ice-sheet dynamics in East Antarctica, Global Planet. Change, 45, 249-263, doi:10.1016/j.gloplacha.2004.09.008, 2005.

Smith, A., Bentley, C., Bingham, R., and Jordan, T.: Rapid subglacial erosion beneath Pine Island Glacier, West Antarctica, Geophys. Res. Lett., 39, L12501, doi:10.1029/2012GL051651, 2012.

Smith, A., Jordan, T., Ferraccioli, F., and Bingham, R.: Influence of subglacial conditions on ice stream dynamics: Seismic and potential field data from Pine Island Glacier, West Antarctica, J. Geophys. Res., 118, 1471-1482, 2013.

Stenoien, M. and Bentley, C.: Pine Island Glacier, Antarctica: A study of the catchment using interferometric synthetic aperture radar measurements and radar altimetry, J. Geophys. Res., 105, 21761-21779, 2000.

Taylor, J., Siegert, M. J., Payne, A. J., and Hubbard, B.: Regionalscale bed roughness beneath ice masses: measurement and analysis, Comput. Geosci., 30, 899-908, 2004.

Vaughan, D.: West Antarctic Ice Sheet collapse - the fall and rise of a paradigm, Climatic Change, 91, 65-79, 2008.

Vaughan, D., Corr, H., Ferraccioli, F., Frearson, N., O‘Hare, A., Mach, D., Holt, J., Blankenship, D., Morse, D., and Young, D.: New boundary conditions for the West Antarctic ice sheet: subglacial topography beneath Pine Island Glacier, Geophys. Res. Lett., 33, L09501, doi:10.1029/2005GL025588, 2006.

Vaughan, D., Corr, H., Bindschadler, R., Dutrieux, P., Gudmundsson, G., Jenkins, A., Newman, T., Vornberger, P., and Wingham, D.: Subglacial melt channels and fracture in the floating part of Pine Island Glacier, Antarctica, J. Geophys. Res., 117, F03012, doi:10.1029/2012JF002360, 2012. 
Weertman, J.: On the sliding of glaciers, J. Glaciol., 3, 33-38, 1957. Weis, M., Greve, R., and Hutter, K.: Theory of shallow ice shelves, Continuum. Mech. Therm., 11, 15-50, 1999.

Wilkens, N.: Pine Island Glacier - a 3D full-Stokes model study, Ph.D. thesis, Universität Hamburg, Hamburg, http://ediss.sub. uni-hamburg.de/volltexte/2014/6735/ (last access: 18 August 2014), 2014.

Wingham, D., Wallis, D., and Shepherd, A.: Spatial and temporal evolution of Pine Island Glacier thinning, 1995-2006, Geophys. Res. Lett., 36, L17501, doi:10.1029/2009GL039126, 2009.
Wright, A. P., Young, D. A., Roberts, J. L., Schroeder, D. M., Bamber, J. L., Dowdeswell, J. A., Young, N. W., Le Brocq, A. M., Warner, R. C., Payne, A. J., Blankenship, D. D., van Ommen, T. D., and Siegert, M. J.: Evidence of a hydrological connection between the ice divide and ice sheet margin in the Aurora Subglacial Basin, East Antarctica, J. Geophys. Res.-Earth, 117, F01033, doi:10.1029/2011JF002066, 2012. 